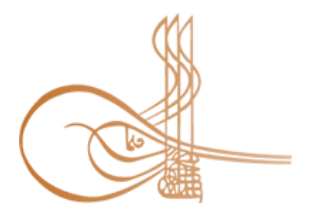

www.turkishstudies.net/social
Turkish Studies - Social Sciences

eISSN: 2667-5617

Research Article / Araştırma Makalesi

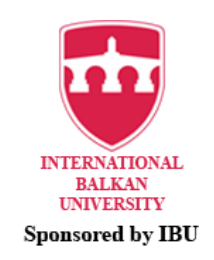

Sponsored by IBU

\title{
Çalışanlar İçin Yaşam Kalitesi Ölçeği’nin (ÇYKÖ) Doğrulayıcı Faktör Analizi: Sosyal Hizmet Uzmanları Örneklemi ${ }^{1}$
}

\author{
The Confirmatory Factor Analysis of the Professional Quality of Life Scale (ProQol): Social \\ Workers' Sample
}

\author{
Mehmet Kırlığlu* - Doğa Başer**
}

\begin{abstract}
Professional quality of life is a concept that reflects the feelings of people (human service providers, assistance professionals, etc.) that provide assistance to people, related to their profession. Professional Quality of Life (ProQoL) Scale was originally designed by Beth Hudnall Stamm to be used as a screening tool for the positive and negative aspects of working in the helping profession. The aim of this study is to do the confirmatory factor analysis of the Professional Quality of Life Scale for employees, which was previously translated by Yeşil et al. (2010) in our country and to evaluate its related psychometric properties in the sample of social workers. Accordingly, the construct validity and reliability of the scale were examined. Considering the findings of confirmatory factor analysis, the sub-dimensions of the scale "Compassion Satisfaction", "Burnout" and "Compassion Fatigue" were examined with the LISREL program and covariance was created among the items in line with the modification recommendations of the related program. In the second stage, it was observed that $\mathrm{x} 2$ / sd, GFI, SRMR, CFI, RMSEA and IFI values of all three sub-dimensions were acceptable. It was seen that the three-factor structure in the original of the scale was proved. When Cronbach Alpha values were analyzed, compassion satisfaction was found to be 0.926 , burnout was 0.738 , and compassion fatigue was 0.825 . As a result of the study, it is seen that the Quality of Life Scale for Employees is a valid and reliable scale. The use of the scale with helping professionals in the field of health, especially in mental health is gaining importance.
\end{abstract}

Structured Abstract: Professional quality of life is a concept that expresses the feelings of person who provide assistance to people by their profession regarding their work. The positive and negative aspects of helping someone affect the quality of professional life. Employees in helping professions face individual, social, national and even international crisis situations. These people can be exemplified as healthcare professionals, social workers, teachers, lawyers, police officers, firefighters, clergy, transportation staff and disaster response teams (Stamm, 2010). The aim of this research is to do the CFA of the Professional Quality

\footnotetext{
${ }^{1}$ Bu çalışmanın verileri 28.01.2019-20.09.2019 tarihleri arasında toplanmıştır.

* Dr. Öğr. Üyesi, Necmettin Erbakan Üniversitesi Sağlık Bilimleri Fakültesi Sosyal Hizmet Bölümü Asts. Prof., Necmettin Erbakan University, Faculty of Health Sciences, Department of Social Work. ORCID 0000-0003-0130-0841

kirlioglumehmet@gmail.com

** Dr. Öğr. Üyesi, Selçuk Üniversitesi, Sağlık Bilimleri Fakültesi, Sosyal Hizmet Bölümü.

Asts. Prof., Selcuk University, Faculty of Health Sciences, Department of Social Work.

ORCID 0000-0002-7451-6590

dogabaser@selcuk.edu.tr

Cite as/ Atıf: Kırlıoğlu, M. \& Başer, D. (2020). Çalışanlar için yaşam kalitesi ölçeği'nin (ÇYKÖ) doğrulayıcı faktör analizi: sosyal hizmet uzmanları örneklemi. Turkish Studies - Social, 15(5), 2561-2573. https://dx.doi.org/10.47356/TurkishStudies.41760

Received/Geliş: 13 February/Şubat 2020

Accepted/Kabul: 20 August/Ağustos 2020

Copyright $($ INTAC LTD, Turkey

Checked by plagiarism software

Published/Yayın: 30 August/Ağustos 2020

CC BY-NC 4.0
} 
of Life Scale in the sample of social workers developed in Stamm $(2005,2010)$ and evaluate the related psychometric properties. Accordingly, the construct validity and reliability of the scale were examined. The research question created for this general purpose is as follows:

Will DFA, conducted in the sample of social workers, support subscales of the Compassion Satisfaction, Burnout and Compassion Fatigue to determine the quality of professional life created by Stamm $(2005,2010)$ ? What can be done to change the structure if DFA does not support it?

A total of 256 social workers were reached for the Confirmatory Factor Analysis (CFA). Social workers who have been working for at least 1 year are included in the sample. $179(69.9 \%)$ of the participants are women and $77(30.1 \%)$ are men. The average age of the participants is $28.84 \pm 7.14$ (the smallest 21 , the largest 70 ), the average working year is $4.97 \pm 6.24$ (the smallest 1 , the largest 46) and the average of individual income is $3966.80 \pm 1224.77$ (the smallest 2500, the largest 10000).

The Professional Quality of Life Scale consists of three scales with 10 items each. These scales are named as Compassion Satisfaction, Burnout and Compassion Fatigue respectively. Data collection was carried out online. The surveey.com website has been used to collect data online. Along with the sociodemographic information of the participants, the Professional Quality of Life Scale was entered on the surveey.com website and the link obtained from the relevant website was sent to the whatsapp application of social workers. SPSS and LISREL package programs were used for data analysis.

As a result, it was observed that $\mathrm{x}^{2} / \mathrm{sd}$, GFI, SRMR, CFI, RMSEA and IFI values were above acceptable limits in all three scales. When Cronbach Alpha values were analyzed, Compassion Satisfaction was found to be 0.926, Burnout was 0.738, and Compassion Fatigue was 0.825.

It is emphasized that the quality of life for employees has become an increasing focus of attention in the field of health (Galiana et al, 2016). The phenomenon of violence in the field of heatlh, which has become an important item for agenda in our country especially in recent years (Uludağ \& Zengin, 2016), draws attention to the application of the quality of life scale to the health personnel as a primary application area. In the literature, it is emphasized that professional staff (such as nurses, social workers, psychologists, and psychiatrists) in the field of mental health who constantly provide care to people who have mental health problems cause compassion fatigue (Ray et al, 2013). In the literature, it is stated that an important factor affecting compassion fatigue and burnout is the working environment, organizational climate and social support. As a matter of fact, Diaconescu (2015) states that the contradictions between intense working hours, time pressure, conflicting work environment, moral dilemmas, professional motivations, and institutional conditions affect the burnout and compassion fatigue in social workers. In a study conducted by Moreno et al. (2015) with 189 social workers, it is seen that burnout is highly prevalent. In the regression analysis, even if there were signs of burnout, informal social support was found to be negatively related to psychological disturbance.

The concept of quality of life for employees is complex in terms of the characteristics of the working environment (in terms of organization and tasks), the personal characteristics of the individual and the traumatic situations of the individual who exposed to in the working environment (Stamm, 2010). This situation requires going beyond quantitative studies in the evaluation of these cases. In this context, mixed pattern researches, in which the Professional Quality of Life Scale is used for employees, will contribute to understanding compassion satisfaction, burnout, and compassion fatigue. It is noteworthy that Collins and Long (2003) conducted a pretest-posttest study with 13 trauma specialists who went to the region and worked with 650 people in 3 years after the bomb attack in 1998, Omagh, Ireland. In the one-year period (August 1998-August 1999), it was found that burnout and compassion fatigue scores of trauma specialists increased and their compassion satisfaction score decreased. In the qualitative dimension of the study, the participants expressed the importance of team spirit and friendship, helping clients to deal with problems in their work, and saw media as a negative factor in reducing the motivation about the crisis.

Keywords: Social Work, The Professional Quality of Life Scale, the Confirmatory Factor Analysis, Burnout, Compassion Fatigue

Öz: Çalışanlar için yaşam kalitesi, (Professional Quality Of Life) mesleği gereği insanlara yardım hizmeti sunan kişilerin (insani hizmet sağlayıcıları-yardım profesyonelleri) yaptıkları işle ilgili hissiyatlarını ifade 
eden bir kavramdır. Çalışanlar için yaşam kalitesi ölçeği (Professional Quality Of Life-ProQOL) Beth Hudnall Stamm tarafindan yardım mesleğinde çalışmanın olumlu ve olumsuz yönleri için bir tarama aracı olarak kullanılmak üzere tasarlanmıştır. Bu çalışmanın amacı daha önce çeviri işlemi ülkemizde Yeşil ve arkadaşları (2010) tarafından yapılan Çalışanlar İçin Yaşam Kalitesi Ölçeği'nin sosyal hizmet uzmanları örnekleminde doğrulayıcı faktör analizini yapmak ve ilgili psikometrik özelliklerini değerlendirmektir. Bu doğrultuda ölçeğin yapı geçerliği ve güvenirliliği incelenmiştir. Doğrulayıcı faktör analizi bulgularına bakıldığında ilk aşamada Ölçeğin Mesleki Tatmin, Tükenmişlik ve Eş Duyum yorgunluğu alt boyutları LISREL programı ile incelenmiş ve LISREL programının modifikasyon önerileri doğrultusunda maddeler arasında kovaryans oluşturulmuştur. İkinci aşamada ise üç alt boyutun da $\mathrm{x}^{2} / \mathrm{sd}$, GFI, SRMR, CFI, RMSEA ve IFI değerlerinin kabul edilebilir uyum değerlerini yakaladığı görülmüsştür. Ölçeğin orijinalindeki üç faktörlü yapının doğrulandığı görülmektedir. Cronbach Alpha değerleri incelendiğinde ise mesleki tatmin 0.926 , tükenmişlik 0.738 , eşduyum yorgunluğu 0.825 olarak bulunmuştur. Sonuç olarak Çalışanlar için yaşam kalitesi ölçeğinin geçerli ve güvenilir bir ölçek olduğu görülmektedir. Ölçeğin yardım profesyonellerinde, genelde sağlık özelde ise ruh sağlığı alanında kullanımı önem kazanmaktadır.

Anahtar Kelimeler: Sosyal Hizmet, Çalışanlar İçin Yaşam Kalitesi, Doğrulayıcı Faktör Analizi, Tükenmişlik, Eşduyum Yorgunluğu

\section{Giriş}

Profesyonel yaşam kalitesi, (Professional Quality Of Life) mesleği gereği insanlara yardım hizmeti sunan kişilerin (insani hizmet sağlayıcıları-yardım profesyonelleri) yaptıkları işle ilgili hissiyatlarını ifade eden bir kavramdır. Birine yardım etmenin olumlu ve olumsuz yönleri profesyonel yaşam kalitesini etkilemektedir. Yardım etme mesleklerinde çalışanlar bireysel, toplumsal, ulusal ve hatta uluslararası kriz durumları ile karşı karşıya kalırlar. Bu kişiler sağlık personelleri, sosyal hizmet uzmanları, öğretmenler, avukatlar, polis memurları, itfaiyeciler, din adamları, ulaşım personelleri ve afet müdahale ekipleri olarak örneklendirilebilir (Stamm, 2010). Yardım profesyonelleri, mesleki ilişki kurarken büyük oranda travmatize olmuş kişilerle karşılaşmaktadır. Artan oranda çocukluk çağı istismarı, aile içi şiddet, doğal afet, savaş ve terörizm mağdurları bu profesyonellerin karşı karşıya olduğu insan profilini özetlemektedir. Bu durum onların doğrudan olmasa da travmatik olayların psikolojik etkilerine maruz kalmalarına neden olmaktadır (Bride, 2007: 63). Thomas ve Otis'in (2010) de belirttiği üzere yardım profesyonellerinden yoğun acı, travma ve çatışmalara sahip bireylerle çalışırken empatik bağlantı (eş duyum) kurabilmeleri beklenmektedir. Mağdur durumdaki kişilerle çalışmak meslek elemanlarının olumsuz etkilenmesini doğurabilmekte, bu da ruh sağlı̆̆ açısından kritik sorunları gündeme getirebilmektedir. Nitekim Goldblatt ve Buchbinder (2003) istismar edilen kadınlarla çalışan kadın öğrencilere yönelik çalışmasında öğrencilerin kadınların deneyimlerini bir kurban olarak anlamaya çalıştıklarını, bununla birlikte acı, suçluluk, utanç, öfke ve çaresizlik duygularını da deneyimlediklerini vurgulamaktadır. Benzer şekilde Siebert'in Kuzey Karolayna'da 1000 sosyal hizmet uzmanı ile yaptığı araştırmada, uzmanların \%19'unun depresif belirtiler gösterdiği, \%16 sının yaşamının bir bölümünde intiharı düşündüğü, $\% 20$ sinin şu anda depresyon tedavisi gördüğü, \%60'ının da geçmişte ya da şu anda kendini depresif olarak değerlendirdiği bulunmuştur (Siebert, 2004). Sonuç olarak travma mağdurları ile çalışanlar travmatik olaya maruz kalmanın yanında, travma yaşayan kişinin acısı, korkusu öfkesi ve çaresizliğini de deneyimlemektedir (Dutton ve Rubinstein, 1995).

Çalışanlar için yaşam kalitesi ölçeği (Professional Quality Of Life-ProQOL) Beth Hudnall Stamm tarafından yardım mesleğinde çalışmanın olumlu ve olumsuz yönleri için bir tarama aracı olarak kullanılmak üzere tasarlanmıştır (Heritage ve ark, 2018). Söz konusu ölçeğin gelişim süreci Charles Figley'in 1980'lerin sonunda geliştirdiği Merhamet Yorgunluğu Ölçeğine dayanmaktadır. Daha sonraki süreçte Figley ve Stamm birlikte çalışmalara başlamış ve 1993 yılında ölçeğe Merhamet Tatmini boyutunu da ekleyerek ölçeğe Merhamet Tatmini ve Yorgunluğu Ölçeği adını vermiş̧lerdir. Son olarak ölçeğin geliştirilmesi ile Çalışanlar İçin Yaşam Kalitesi Ölçeği ortaya 
çıkmıştır (Stamm, 2010). Profesyonel yaşam kalitesi olumlu (Merhamet Tatmini) ve olumsuz (Merhamet Yorgunluğu) olmak üzere iki ana boyutu içerir. Merhamet tatmini mesleğini iyi yapabilme ile ilgili hissedilen tatmin/zevk ile ilgilidir. Meslek elemanları çalışmaları sırasında başkalarına yardım etmekten ve toplumun yararına katkıda bulunmaktan olumlu bir hissiyat duyuyorsa bu durum merhamet tatminini yansitmaktadır. Merhamet yorgunluğu ise Stamm'ın teorisinde iki ayrı alt bölüme ayrılmıştır. Birinci bölüm tükenmişlik başlığı ile hayal kırıklığı, öfke ve tükenmişliğe özgü depresyona gönderme yaparken, ikinci bölüm ikincil travmatik stres başlı̆̆ ile kişinin yaptığı işle alakalı korkularından ve travmalarından kaynaklanan olumsuz duyguları ifade eder (Stamm, 2010). Çalışanlar İçin Yaşam Kalitesi Ölçeği'nin ülkemizde ilk çeviri işlemi Yeşil ve arkadaşları (2010) tarafından gerçekleştirilmiştir. Bu çalışmada compassion satisfaction yani merhamet tatmini "mesleğini iyi yapabilme ile ilgili hissedilen tatmin/zevk ile ilgilidir" açıklaması ile bağlantılı olarak "mesleki tatmin" olarak Türkçeleştirilmiştir. Merhamet yorgunluğu başlığı altındaki tükenmişlik başlığı aynen Türkçeleştirilirken ikincil travmatik stres alt başlığı ise "eşduyum yorgunluğu” adı altında Türkçeleştirilmiştir. Hali hazırda literatürde mevcut çeviriler kullanıldığı için bu çalışmada da ilk çeviri işlemini yapan yazarların kavramları üzerinden gidilmiştir. Bu noktada bir diğer önemli konu da her ne kadar merhamet tatmini, tükenmişlik ve eş duyum yorgunluğu kavramları birbiri ile örtüssen kavramlar olarak belirtilmişse de Stamm, Çalışanlar İçin Yaşam Kalitesi Ölçeği'nin üç alt boyutunun her birinin psikometrik olarak benzersiz olduğunu ve birleştirilmemesi gerektiğini belirtmektedir. Örneğin, bir kişinin hem eş duyum yorgunluğu hem de mesleki tatmin ölçeklerinden eşzamanlı olarak yüksek bir puanı olması mümkündür (Heritage ve ark, 2018).

\section{Araştırmanın Gerekçesi ve Önemi}

Stamm $(2005,2010)$ tarafindan ortaya koyulan Çalışanlar İçin Yaşam Kalitesi Ölçeği birçok dile çevrilerek kullanılmaktadır. Bu diller arasında Türkçe de yer almaktadır. Bu doğrultuda isteyenler proqol.org sitesini ziyaret ederek ve gerekli izni alarak ilgili ölçeği kullanabilirler. Çalışanlar İçin Yaşam Kalitesi Ölçeği’nin çeviri işlemi Yeşil ve ark. (2010) tarafindan gerçekleştirilmiştir. Ardından Kısa Semptom Tarama Envanteri (Şahin ve Durak, 1994) ve Tükenmişlik Ölçeği (Ergin, 1992) ile Çalışanlar İçin Yaşam Kalitesi Ölçeği arasındaki korelasyon katsayılarına bakılmıştır. Ancak Çalışanlar İçin Yaşam Kalitesi Ölçeği'ni oluşturan alt ölçekler birçok çalışmada (Bozgeyikli, 2012; Karakose ve Bozgeyikli, 2012; Taycan ve ark., 2013; Günüşen ve ark., 2018; Dinç ve Ekinci, 2019; Yılmaz ve Üstün, 2019; Kılıç ve ark., 2020) kullanılmış olmasına rağmen Stamm $(2005,2010)$ tarafindan ortaya koyulan 10'ar maddelik alt ölçeklerin doğrulanması gerçekleştirilmemiştir. Literatürde Doğrulayıcı Faktör Analizi (DFA) yapılmayan ölçeklerin kullanılması eleştirilmektedir (Fietzer ve Ponterotto 2015; Lu ve ark., 2018). Birçok çalışmada benzer durumu görmek mümkündür (Shevlin ve Adamson, 2005; Li ve ark., 2009; Rey ve ark., 2014; Shayan ve ark., 2015; Kashyap ve Singh, 2017; Tabatabaei ve Rasouli, 2018; Hjelle ve ark., 2019). Bu nedenle ProQOL Office of the Center for Victims of Torture adli merkezden Çalışan İçin Yaşam Kalitesi Ölçeği'ni oluşturan alt ölçeklerin DFA'sının sosyal hizmet uzmanları örnekleminde yapabilmek için izin alınmıştır. Son olarak Stamm $(2005,2010)$ tarafından ortaya koyulan Çalışanlar İçin Yaşam Kalitesi Ölçeği'nin ülkemizde DFA'sının yapıldığı ilk çalışma olması açısından önem taşımaktadır.

\section{Araştırmanın Amacı}

$\mathrm{Bu}$ araştırmanın amacı Stamm $(2005,2010)$ geliştirilen Çalışanlar İçin Yaşam Kalitesi Ölçeği'nin sosyal hizmet uzmanları örneklemin DFA'sını yapmak ve ilgili psikometrik özelliklerini değerlendirmektir. Bu doğrultuda ölçeğin yapı geçerliği ve güvenirliliği incelenmiştir. Bu genel amaca istinaden oluşturulan araştırma sorusu şu şekildedir:

- Sosyal hizmet uzmanları örnekleminde yapılan DFA, çalışanlar için yaşam kalitesini belirlemeye yönelik Stamm $(2005,2010)$ tarafından elde edilen 10'ar maddelik Mesleki 
Tatmin, Tükenmiş ve Edşduyum Yorgunluğu ölçeklerini destekleyecek midir? Eğer DFA desteklemezse yapıyı değiştirmek için ne yapılabilir?

\section{Yöntem}

Araştırmaya başlamadan önce Çalışanlar İçin Yaşam Kalitesi Ölçeği'ni kullanabilmek ve sosyal hizmet uzmanları örnekleminde DFA yapabilmek için proqol.org sitesi üzerinden form doldurularak ProQOL Office of the Center for Victims of Torture adlı merkezden izin alınmıştır.

\section{Katılımcilar}

DFA'nın kaç kişinin katılımı ile yapılacağı hususunda farklı görüşler olsa da bu noktada Kline (2011) en az 100 örneklemle çalışılması gerektiğini ve bu sayının 400 ve üstüne çıkmamasını gerektiğini ifade etmektedir. 400 ve üstüne çıkması durumunda Tip 1 hatanın yaşanabileceğini belirtmektedir. Buna dayanarak Doğrulayıcı Faktör Analizi (DFA) için toplamda 256 sosyal hizmet uzmanına ulaşılmışıır. En az 1 yıldır çalışıyor olan sosyal hizmet uzmanları örnekleme dâhil edilmiştir. Katılımcıların 179'u (\%69.9) kadın, 77'si (\%30.1) erkektir. Katılımcıların yaş

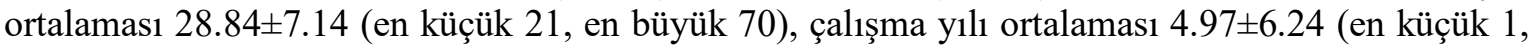
en büyük 46) ve bireysel gelir ortalaması $3966.80 \pm 1224.77$ (en küçük 2500, en büyük 10000) şeklindedir.

\section{Veri Toplama Araçları}

Orijinal ismi Professional Quality of Life Scale olan Çalışanlar İçin Yaşam Kalitesi Ölçeği her biri 10 madde olan üç ölçekten oluşmaktadır. Bu ölçekler sırasıyla mesleki tatmin, tükenmişlik ve eşduyum yorgunluğu olarak isimlendirilmektedir. Türkçe dahil 27 dile çevrilmiş ve hali hazırda kullanılmaktadır. Ölçeğin Türkçe formuna https://www.proqol.org/uploads/ProQol-IV_Turkish.pdf linki ile ulaşılabilir. Diğer dillere çevrilen ölçek formlarına yine proqol.org sitesi üzerinden ulaşılmaktadır. Ölçek Stamm $(2005,2010)$ tarafından yapılan çalışmalar neticesinde ortaya çıkmıştır. Araştırmalarda bu üç ölçeğin maddeleri karışık olarak kullanılmaktadır. Ancak ölçeklerin birbiri ile ilişkisi yoktur. Bu nedenle ölçekten alınacak toplam puan bulunmamaktadır. Karışık olarak tek bir çatı altında kullanılmalarına rağmen her bir ölçeğin kendine ait puanı bulunmaktadır. Mesleki tatmin ifadeleri 3, 6, 12, 16, 18, 20, 22, 24, 27 ve 30. maddelerini kapsamaktadır. Ölçekten alınan puan arttıkça mesleki tatminin de arttı̆̆ 1 belirtilmektedir. Tükenmişlik ifadeleri $1,4,8,10$, $15,17,19,21,26$ ve 29. maddelerini kapsamaktadır. Ölçekten alınan puan arttıkça tükenmişliğin de arttığı belirtilmektedir. Eş duyum yorgunluğuna ilişkin ifadeler 2, 5, 7, 9, 11, 13, 14, 23, 25 ve 28. maddelerini kapsamaktadır. Ölçekten alınan puan arttıkça eş duyum yorgunluğunun da arttığı belirtilmektedir. Ölçekteki 1, 4, 15, 17 ve 29. maddeler ters puanlanmaktadır. Ölçek 6'lı likerttir. Ancak 0-5 arasında derecelendirilmektedir. 0 rakamı hiç bir zaman anlamına gelmekte iken 5 rakamı ise çok sık anlamına gelmektedir. Mesleki tatmin, tükenmişlik ve eşduyum yorgunluğuna ait Cronbach Alpha değerleri sırasıyla 0.87; 0.72 ve 0.80 olarak bulunmuştur.

\section{Verilerin Toplanması}

Verilerin toplanması online olarak gerçekleştirilmiştir. Online olarak verileri toplayabilmek amacıyla surveey.com web sitesi kullanılmıștır. Katılımcılara ait sosyo-demografik bilgilerle birlikte Çalışanlar İçin Yaşam Kalitesi Ölçeği surveey.com web sitesine girilmiş ve ilgili web sitesinden elde edilen link sosyal hizmet uzmanlarının whatsapp uygulamasına tek tek gönderilmiştir. Araştırmacıların sosyal hizmet bölümünde akademisyen olması ve Sosyal Hizmet Uzmanları Derneği'ne üye olmaları veri toplamayı kolaylaştırmıştır. Veriler 28.01.201920.09.2019 tarihleri arasında toplanmıştır.

\section{Verilerin Analizi}

Verilerin analizi için SPSS ile LISREL paket programlanı kullanılmıştır. SPSS paket programı ile verilerin normal dağılımı ve güvenirlik analizleri yapılmıştır. Normal dağılım için üç 
aşamalı bir yol izlenmiştir. Birincisi $\mathrm{p}>0.05$ olmalıdır. Bu koşulu sağlamıyorsa skewness ve kurtosis değerleri incelenmiştir. Bu değerlerin \pm 1.5 arasında olması (Tabachnick ve Fidell, 2015) istenmektedir. Üçüncüsü skewness ve kurtosis değerleri ile birlikte histogram tabloları da incelenerek son karar verilmiştir.

LISREL paket programı aracılığı ile Stamm $(2005,2010)$ tarafindan oluşturulan yapının doğrulanması DFA ile gerçekleştirilmiştir. Stamm $(2005,2010)$ tarafindan oluşturulan 10 maddelik mesleki tatmin, 10 maddelik tükenmişlik ve 10 maddelik eşduyum yorgunluğu ifadeleri ile kurulan modellerin uygunluğuna karar verebilmek için çeşitli uyum indekslerinden faydalanılmıştır. Literatürde uyum indeksleri ile ilgili olarak kesin bir sınırlar çizilemediği, standart olarak sunulan uyum indekslerinin olmadığ belirtilmektedir (Crowley ve Fan, 1997; Munro, 2005; Şimşek, 2007). Bu nedenle de çeşitli araştırmalardan (Aytaç ve Öngen, 2012; Kıraç, 2019; Dinç ve Ekinci, 2019; Öztürk ve Kıraç, 2019; Kalaycı-Kırlığlu ve ark., 2020) faydalanarak x²/sd, RMSEA, CFI, IFI, SRMR ve GFI gibi uyum indekslerinin kullanılmasına karar verilmiştir. Bu noktada kabul edilebilir değerler sırasıyla $<5 ;<0.10 ;<0.90 ;<0.90 ; 0.05-0.10$ ve $<0.90$ olmalıdır. Benzer şekilde iyi uyum değerleri de sırasıyla $<2 ;<0.08 ;<0.95 ;<0.95 ; 0.00-0.05$ ve $<0.95$ olmalıdır (Schermelleh-Engel ve ark., 2003; Hooper ve ark 2008). Kabul edilebilir ve iyi uyum değerleri bu ölçütlere göre değerlendirilmiştir.

\section{Bulgular}

Çalışanlar İçin Yaşam Kalitesi Ölçeği'nin DFA'sına ilişkin bulguları vermeden önce iki husus hakkında bilgi vermek gerekmektedir. Birinci bilgi, model uyumunu iyileştirmek için modifikasyon önerileri doğrultusunda gerçekleştirilen kovaryanslara ilişkindir (Seçer, 2017). LISREL programı ki-kare değerini düşürecek ve model uyumunu iyileştirecek öneriler vermektedir. $\mathrm{Bu}$ öneriler içerisinde küçüklü-büyüklü ki-kare değerlerini düşüren değerler yer almakta iken ki-kare değerini 30 ve üstünde düşüren kovaryanslar dikkate alınmıştır. İkinci bilgi ise her bir maddenin sahip olduğu $t$ değerlerine ilişkindir. Modeldeki her bir maddenin 0.05 düzeyinde anlamlı olması beklenmektedir. Ĕ̆er bir madde 0.05 düzeyin anlamlı değilse o maddenin modelden çıkarılması gerektiği ifade edilmektedir (Özüdoğru ve ark., 2018). Bu nedenle ölçekteki her bir maddenin $t$ değerleri kontrol edilmiş ve üç ölçeğe ait olan tüm maddelerin 0.01 düzeyin anlamlı olduğu tespit edilmiştir. 


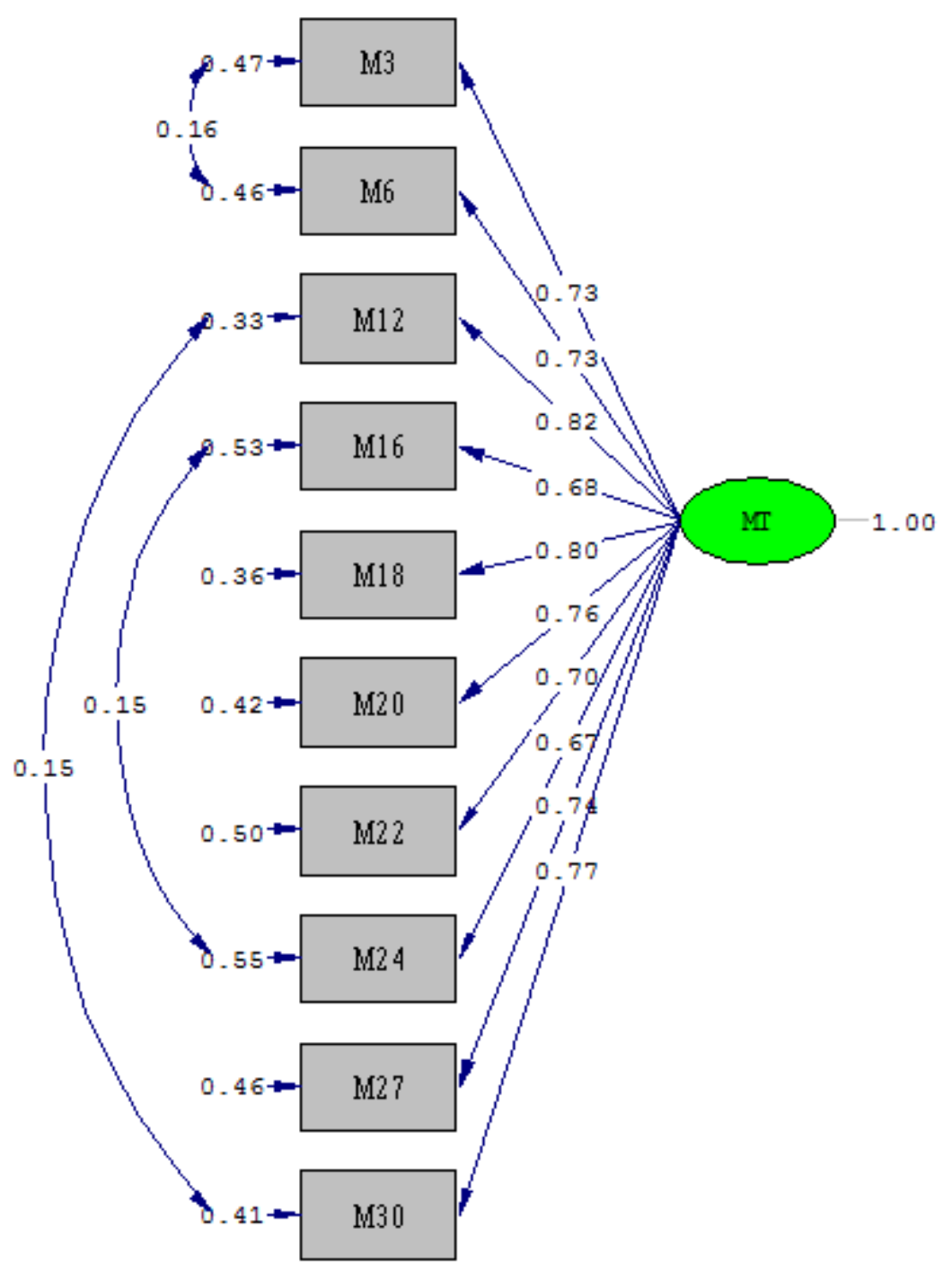

Şekil 1. Mesleki Tatmin Maddelerine İlişkin Yapılan DFA

Stamm $(2005,2010)$ çalışanlar için yaşam kalitesini belirleyebilmek amaciyla üç saç ayağından birincisini mesleki tatmin üzerine kurmuştur. Mesleki tatmini belirleyen maddelerle yapılan DFA sonucu Şekil 1'de yer almaktadır. LISREL programının modifikasyon önerileri doğrultusunda maddeler arasında kovaryans oluşturulmuştur. Buna göre M3-M6; M12-M30 ve M16-M24 maddeleri arasında kovaryans oluşturulmuştur. Modifikasyon önerileri ile gerçekleştirilen kovaryanslar sonrasında yapılan analiz sonucunda $\mathrm{x}^{2}=124.59 ; \mathrm{sd}=32 ; \mathrm{x}^{2} / \mathrm{sd}=3.89$; RMSEA $=0.09 ; \quad \mathrm{CFI}=0.97 ; \mathrm{IFI}=0.97 ; \mathrm{SRMR}=0.046 ; \mathrm{GFI}=0.91$ değerleri tespit edilmiştir. $\mathrm{Bu}$ sonuçlara göre $\mathrm{x}^{2} / \mathrm{sd}$, RMSEA ve GFI değerlerinin kabul edilebilir; CFI, SRMR ve IFI, değerlerinin de iyi uyum değerlerini yakaladığı görülmektedir. bulunmuştur.

DFA yapılan mesleki tatmin maddelerine ilişkin Croonbach Alpha değeri 0.926 olarak 


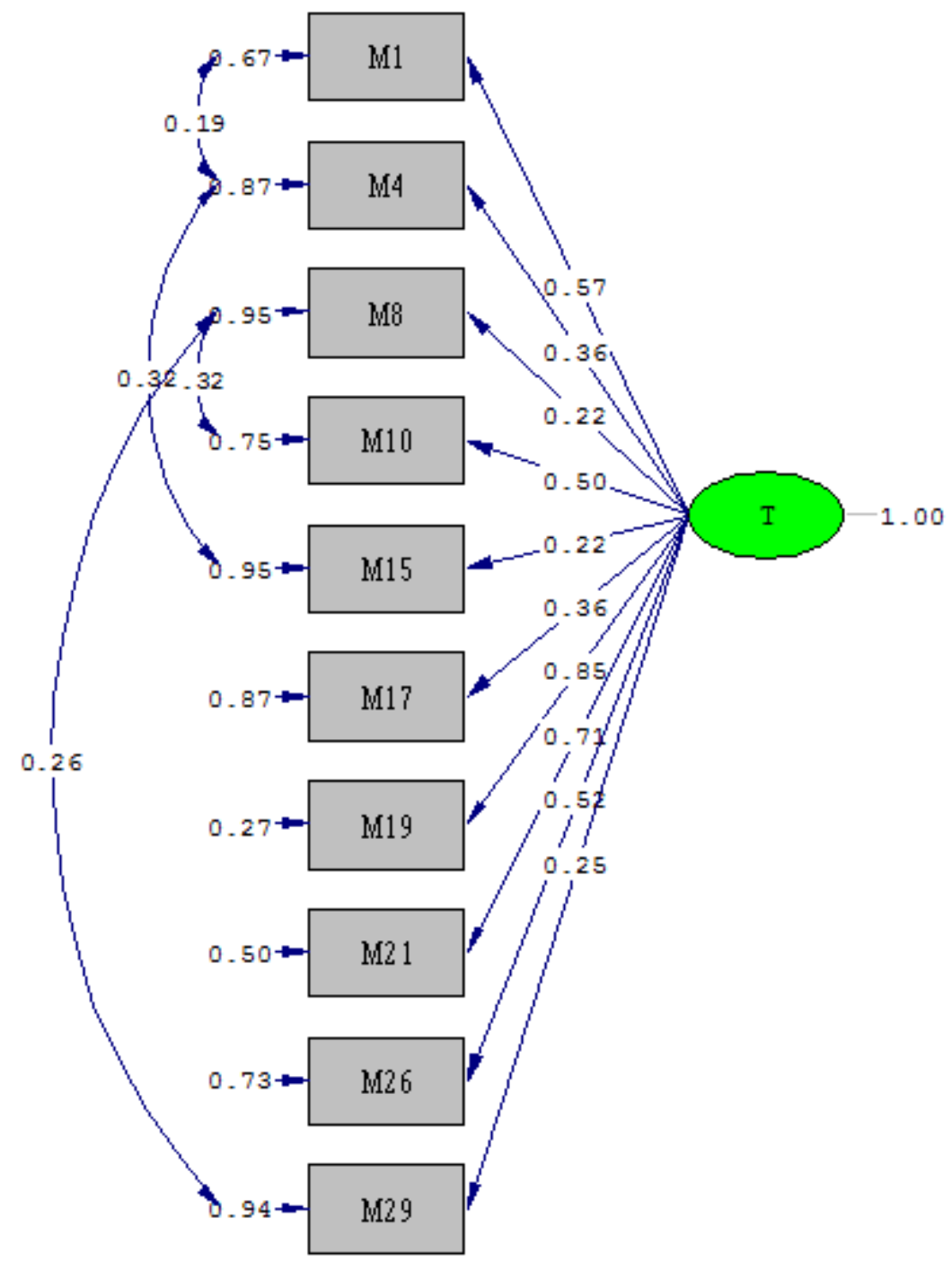

Şekil 2. Tükenmişlik Maddelerine İlişkin Yapılan DFA

Stamm $(2005,2010)$ çalışanlar için yaşam kalitesini belirleyebilmek amacıyla üç saç ayağından ikincisini tükenmişlik üzerine kurmuştur. Tükenmişliği belirleyen maddelerle yapılan DFA sonucu Şekil 2'de yer almaktadır. LISREL programının modifikasyon önerileri doğrultusunda maddeler arasında kovaryans oluşturulmuştur. Buna göre M1-M4; M4-M15; M8-M10 ve M8-M29 maddeleri arasında kovaryans oluşturulmuştur. Modifikasyon önerileri ile gerçekleştirilen kovaryanslar sonrasinda yapılan analiz sonucunda $\mathrm{x}^{2}=113.50 ; \mathrm{sd}=31 ; \mathrm{x}^{2} / \mathrm{sd}=3.66 ; \mathrm{RMSEA}=0.09$; $\mathrm{CFI}=0.91$; $\mathrm{IFI}=0.91$; $\mathrm{SRMR}=0.084$; $\mathrm{GFI}=0.91$ değerleri tespit edilmiştir. $\mathrm{Bu}$ sonuçlara göre $\mathrm{x}^{2} / \mathrm{sd}$, RMSEA, CFI, SRMR, IFI ve GFI değerlerinin kabul edilebilir değerleri yakaladığı görülmektedir.

DFA yapılan tükenmişlik maddelerine ilişkin Croonbach Alpha değeri 0.738 olarak bulunmuştur. 


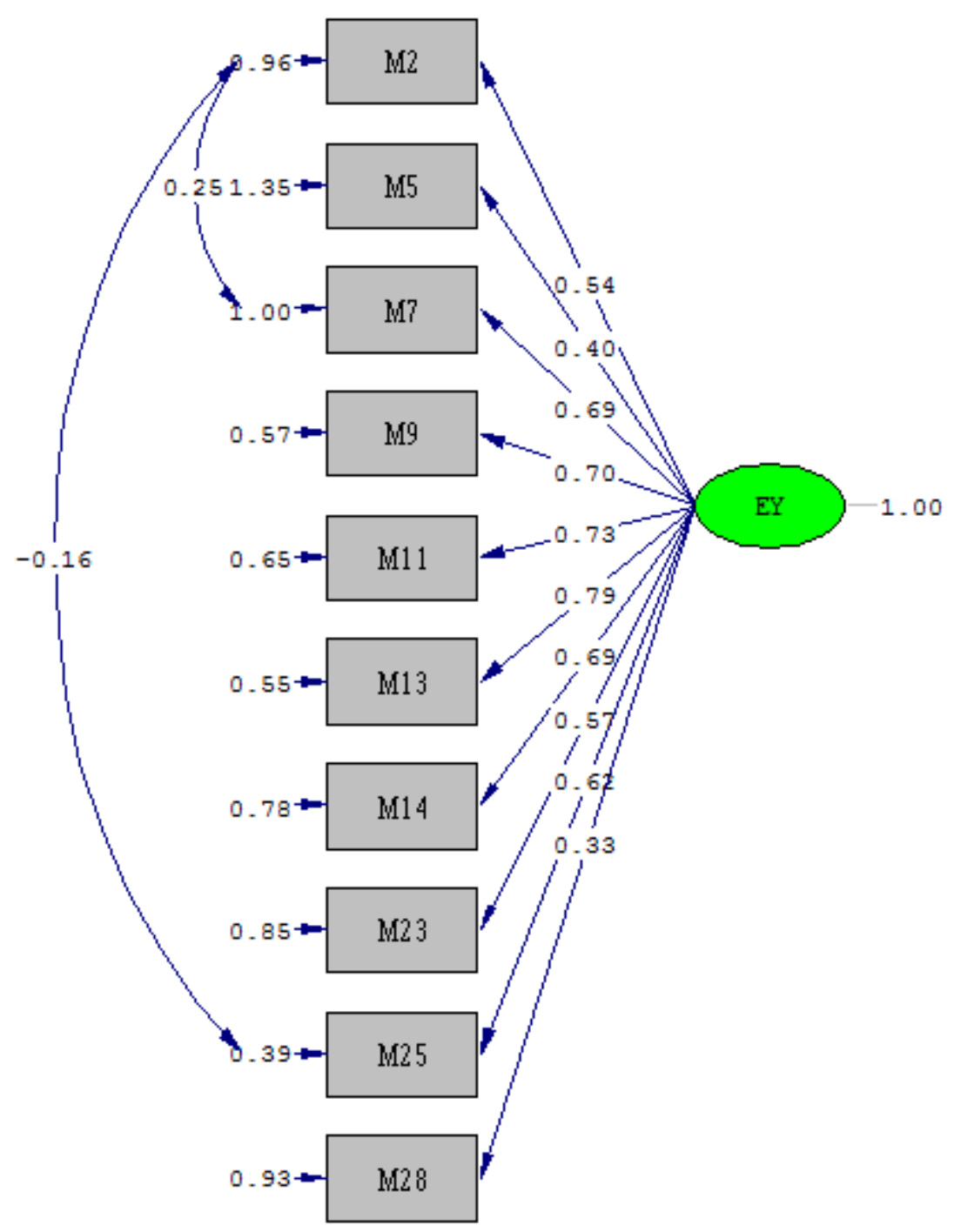

Şekil 3. Eşduyum Yorgunluğu Maddelerine İlişkin Yapılan DFA

Stamm $(2005,2010)$ çalışanlar için yaşam kalitesini belirleyebilmek amacıyla üç saç ayağından üçüncüsünü eşduyum yorgunluğu üzerine kurmuştur. Eşduyum yorgunluğunu belirleyen maddelerle yapılan DFA sonucu Şekil 3'de yer almaktadır. LISREL programının modifikasyon önerileri doğrultusunda maddeler arasında kovaryans oluşturulmuştur. Buna göre M2-M7 ve M2M25 maddeleri arasında kovaryans oluşturulmuştur. Modifikasyon önerileri ile gerçekleştirilen kovaryanslar sonrasinda yapılan analiz sonucunda $\mathrm{x}^{2}=83.09 ; \mathrm{sd}=33 ; \mathrm{x}^{2} / \mathrm{sd}=2.51$; RMSEA $=0.07$; $\mathrm{CFI}=0.96$; IFI=0.96; SRMR $=0.057$; GFI=0.94 değerleri tespit edilmiştir. Bu sonuçlara göre $\mathrm{x}^{2} / \mathrm{sd}$, GFI ve SRMR eğerlerinin kabul edilebilir; CFI, RMSEA ve IFI değerlerinin de iyi uyum değerlerini yakaladığı görülmektedir.

DFA yapılan eşduyum yorgunluğu maddelerine ilişkin Croonbach Alpha değeri 0.825 olarak bulunmuştur.

\section{Tartışma, Sonuç ve Öneriler}

Çalışanlar İçin Yaşam Kalitesi Ölçeğinin doğrulayıcı faktör analizi ile incelenmesini amaçlayan bu çalışmada söz konusu ölçeğin Mesleki Tatmin, Tükenmişlik ve Eşduyum yorgunluğu alt ölçekleri LISREL programı ile incelenmiş ve LISREL programının modifikasyon önerileri 
doğrultusunda maddeler arasında kovaryans oluşturulmuştur. Sonuç olarak üç alt boyutunda da $\mathrm{x}^{2} / \mathrm{sd}$, GFI, SRMR, CFI, RMSEA ve IFI değerlerinin kabul edilebilir sınırların üstünde olduğu görülmüştür. Cronbach Alpha değerleri incelendiğinde ise mesleki tatmin 0.926, tükenmişlik 0.738, eşduyum yorgunluğu 0.825 olarak bulunmuştur. Çalışanlar İçin Yaşam Kalitesi Ölçeğinin faktör yapısı ile ilgili yeterli çalışma olmadığı literatürde vurgulanmaktadır (Galiana ve ark, 2016). Galiana ve arkadaşlarının (2016) Çalışanlar İçin yaşam kalitesi ölçeğini İspanya ve Brezilya örnekleminde yaptıkları doğrulayıcı faktör analizi çalışmasında 3 faktörlü yapıyı doğrulamakla birlikte tükenmişlik boyutundaki ters maddelerin bir katkı sağlamadığını ölçek üzerinde olumsuz etki ettiğini belirtmişlerdir. Ayrıca yazarlar eş duyum yorgunluğu ve tükenmişliğin sadece psikometrik açıdan farklı yapılar olmadıklarını ampirik açıdan da ayrı boyutlar olduğunu belirtmişlerdir. Samson ve arkadaşlarının (2016) İbraniceye yönelik geçerlik-güvenirlik çalışmasında ise doğrulayıcı faktör analizinin iyi uyum değerlerini sağlamadığı, açıklayıcı faktör analizinde ise mevcut alt boyutlar çerçevesinde 23 maddelik bir sonuca ulaşıldığ 1 belirtilmiştir. Yazarlar eş duyum yorgunluğu ve tükenmişlik alt boyutu ile ilgili ileri araştırmaların gerekliliğinin altını çizmişlerdir.

Çalışanlar için yaşam kalitesinin sağlık alanında artan bir ilgi odağı haline geldiği vurgulanmaktadır (Galiana ve ark, 2016). Özellikle son yıllarda ülkemizde önemli bir gündem maddesi haline gelen sağlikta şiddet olgusu (Uludağ ve Zengin, 2016) Çalışanlar İçin Yaşam Kalitesi Ölçeği'nin öncelikli bir uygulama alanı olarak sağlık personellerine uygulanmasına dikkat çekmektedir. Literatürde özellikle ruh sağlığı alanında meslek elemanlarının (hemşire, sosyal hizmet uzmanı, psikolog ve psikiyatr gibi) ruh sağlı̆g sorunu olan kişilere sürekli olarak bakım vermeleri ve ilgilenmelerinin eşduyum yorgunluğuna yol açabileceği vurgulanmaktadır (Ray ve ark, 2013). Literatürde eşduyum yorgunluğu ve tükenmişliği etkileyen önemli bir unsurun çalışma ortam1, örgüt iklimi ve sosyal destek olduğu belirtilmektedir. Nitekim Diaconescu (2015) sosyal hizmet uzmanlarında tükenmişlik ve eşduyum yorgunuluğunu yoğun çalışma saatleri, zaman baskısı, çatışmalı iş ortamı, ahlaki ikilemler, mesleki motivasyonlar ve kurumsal koşullar arasındaki çelişkilerin etkilediğini belirtmektedir. Moreno ve arkadaşlarının (2015) 189 sosyal hizmet uzmanları ile yaptıkları araştırmada ise psikolojik rahatsızlık ve duygusal boyut ön planda olmak üzere tükenmişliğin yüksek düzeyde yaygın olduğu görülmektedir. Yapılan regresyon analizinde tükenmişlik belirtileri olsa bile informal sosyal desteğin psikolojik rahatsızlık ile negatif ilişkili olduğu görülmüştür.

Çalışanlar için yaşam kalitesi kavramı çalışma ortamının özellikleri (organizasyon ve görevler açısından) bireyin kişisel özellikleri ve çalışma ortamında maruz kaldığı travmatik durumlar açısından karmaşıktır (Stamm, 2010) Bu durum söz konusu olguların değerlendirilmesinde nicel çalışmaların ötesine geçilmesini gerektirmektedir. $\mathrm{Bu}$ çerçevede çalışanlar için yaşam kalitesi ölçeğinin kullanıldığı karma desen araştırmalar mesleki tatmini, eşduyum yorgunluğu ve tükenmişliğin anlaşılmasına katk1 sağlayacaktır. Nitekim Collins ve Long'un (2003) Omagh-İrlandada 1998 yılında meydana gelen bombalı saldırının üzerine bölgeye giden ve bölge halkı ile 3 senede 650 kişi ile çalışan 13 travma uzmanı ile yaptığı ön test son test çalışmasında (Ağustos 1998-Ağustos 1999 kapsayan bir senelik süreçte) tükenmişlik ve merhamet yorgunluğu puanlarının arttığı, merhamet tatmini puanın ise düştüğü bulunmuştur. Çalışmanın nitel boyutunda katılımcılar çalışmalarında sorunlarla başa çıkmada takım ruhunun ve arkadaşlığın, müracaatçılara yardımcı olabilmenin önemini dile getirmişler, medyanın kriz durumuna karşı tavrının motivasyonlarını düşürmede olumsuz bir etken olarak görmüşlerdir.

\section{Kaynakça}

Aytaç, M., \& Öngen, B. (2012). Doğrulayıcı faktör analizi ile yeni çevresel paradigma ölçeğinin yapı geçerliliğinin incelenmesi. İstatistikçiler Dergisi: Ístatistik ve Aktüerya, 5(1), 14-22. 
Bozgeyikli, H. (2012). Self efficacy as a predictor of compassion satisfaction, burnout, compassion fatigue: A study on psychological counselors. African Journal of Business Management, 6(2), 646-651.

Bride, B. E. (2007). Prevalence of secondary traumatic stress among social workers. Social Work, $52(1), 63-70$.

Collins, S. \& Long A.. (2003). Too tired to care? The psychological effects of working with trauma. Journal of Psychiatric and Mental Health Nursing, 2003; 10,(1): 17-27.

Crowley, S. L. \& Fan, X. (1997). Structural equation modeling: Basic concepts and applications in personality assessment research. Journal of Personality Assessment, 68(3), 508-31.

Diaconescu, M. (2015). Burnout, secondary trauma and compassion fatigue in social work. Revista de Asistent Sociaßanul., 14 (3): 57-63.

Dinç, S. \& Ekinci, M. (2019). Turkish adaptation, validity and reliability of Compassion Fatigue Short Scale. Psikiyatride Güncel Yaklaşımlar, 11, 192-202.

Dutton, M.A. \& Rubinstein, F.L. (1995). Woking with People with PTSD: Research Implications. In C.R. Figley (Ed.), Compassion Fatigue: Coping with Secondary Traumatic Stress Disorder in Those who Treat the Traumatised (pp. 82- 100). Brunner/Mazel Publishers.

Ergin, C. (1992). Doktor ve hemşirelerde tükenmişlik ve Maslach tükenmişlik ölçeğinin uyarlanması. (VII. Ulusal Psikoloji Kongresi Bilimsel Çalışmaları), VII. Ulusal Psikoloji Kongresi Düzenleme Kurulu ve Türk Psikologlar Derneği Yayını. Hacettepe Üniversitesi.

Fietzer, A. W. \& Ponterotto, J. (2015). A psychometric review of instruments for social justice and advocacy attitudes. Journal for Social Action in Counseling \& Psychology, 7(1), 19-40.

Galiana, L., Arena, F., Oliver, A., Sansó, N. \& Benito, E. (2017). Compassion satisfaction, compassion fatigue, and burnout in Spain and Brazil: ProQOL validation and cross-cultural diagnosis. Journal of pain and symptom management, 53(3), 598-604.

Goldblatt, H. \& Buchbinder, E. (2003). 'Challenging gender roles: the impact on female social work students working with abuse women', Journal of Social Work Education, vol. 39, no. 2, 255-279.

Günüşen, N. P., Wilson, M. \& Aksoy, B. (2018). Secondary traumatic stress and burnout among Muslim nurses caring for chronically ill children in a Turkish hospital. Journal of Transcultural Nursing, 29(2), 146-154.

Heritage, B., Rees, C. S. \& Hegney, D. G. (2018). The ProQOL-21: A revised version of the Professional Quality of Life (ProQOL) scale based on Rasch analysis. PloS one, 13(2): e0193478, https://doi.org/10.1371/journal.pone.0193478

Hjelle, E. G., Bragstad, L. K., Zucknick, M., Kirkevold, M., Thommessen, B. \& Sveen, U. (2019). The General Health Questionnaire-28 (GHQ-28) as an outcome measurement in a randomized controlled trial in a Norwegian stroke population. BMC psychology, 7(18), https://doi.org/10.1186/s40359-019-0293-0

Hooper, D., Coughlan, J. \& Mullen, M. (2008). Structural equation modelling: Guidelines for determining model fit. The Electronic Journal of Business Research Methods, 6(1), 53-60.

Kalayc1-Kırlığlu, H.İ., Daşbaş, S. \& Karakuş, Ö. (2020). Sosyal Hizmet Uygulamasında Mesleki Uygunluk Ölçeği: Geçerlilik ve güvenirlik. Toplum ve Sosyal Hizmet, 31(3), 793-822. 
Karaköse, B. \& Bozgeyikli, H. (2012). Örgütsel bağl1lık ve çalışma yaşamı kalitesi arasındaki ilişki: Rehberlik araştırma merkezlerinde çalışan personel üzerine bir çalışma. Hak $\dot{I}_{S ̧}$ Uluslararası Emek ve Toplum Dergisi, 1(2), 164-180.

Kashyap, G. C. \& Singh, S. K. (2017). Reliability and validity of general health questionnaire (GHQ-12) for male tannery workers: a study carried out in Kanpur, India. BMC psychiatry, 17(1), 102.

Kılıç, D., Bakan, A. B., Aslan, G. \& Uçar, F. (2020). Onkoloji birimleri ve yoğun bakım ünitelerinde çalışan hemşirelerde etik duyarlılık ve merhamet yorgunluğu arasındaki ilişkinin incelenmesi. Adnan Menderes Üniversitesi Sağllk Bilimleri Fakültesi Dergisi, 4(1), 20-29

Kıraç, R. (2019). Nomofobinin dikkat eksikliğine etkisi. OPUS Uluslararası Toplum Araştırmaları Dergisi, 14(20), 1095-1114.

Kline, R. B. (2011). Principles and practice of structural equation modeling. Guilford.

Li, W. H., Chung, J. O., Chui, M. M. \& Chan, P. S. (2009). Factorial structure of the Chinese version of the 12-item General Health Questionnaire in adolescents. Journal of Clinical Nursing, 18(23), 3253-3261.

Lu, J., Woo, H. \& Huffman, K. (2018). Spiritual competency scale: A confirmatory factor analysis. Measurement and Evaluation in Counseling and Development, 51(4), 219-234.

Moreno, E.S., Roldan I.N.L., Peralte L.P.G., Roda A.B.L. (2015). Burnout, informal social support and psychological distress among social workers. British Journal of Social Work, 45: 2368-2386.

Munro, B. H. (2005). Statistical methods for health care research. Lippincott Williams \& Wilkins.

Öztürk, Y. E. \& Kıraç, R. (2019). Hekim Merhameti Önündeki Engeller Ölçeğinin Türkçe geçerlilik ve güvenilirlik çalışması. Uluslararası Sağlık Bilimleri ve Yönetimi Kongresi (s. 441-446), İstanbul.

Özüdoğru, H. Y., Kan, A., Yaman, E. \& Uslu, L. (2018). Yerel Halkın Suriyelilere Yönelik Tutum Ölçeği geliştirme çalışması. Sosyal Politika Çalışmaları Dergisi, 18(40/2), 115-140.

Ray, S. L., Wong, C., White, D. \& Heaslip, K. (2013). Compassion satisfaction, compassion fatigue, work life conditions, and burnout among frontline mental health care professionals. Traumatology, 19(4), 255-267.

Rey, J. J., Abad, F. J., Barrada, J. R., Garrido, L. E. \& Ponsoda, V. (2014). The impact of ambiguous response categories on the factor structure of the GHQ-12. Psychological assessment, 26(3), 1021-1030

Samson, T., Iecovich, E. \& Shvartzman, P. (2016). Psychometric characteristics of the Hebrew version of the Professional Quality-of-Life Scale. Journal of pain and symptom management, 52(4), 575-581.

Seçer, İ. (2017). SPSS ve LISREL ile pratik veri analizi analiz ve raporlaştırma. Anı Yayıncılık.

Shayan, Z., Pourmovahed, Z., Najafipour, F., Abdoli, A. M., Mohebpour, F. \& Najafipour, S. (2015). Factor structure of the General Health Questionnaire-28 (GHQ-28) from infertile women attending the Yazd Research and Clinical Center for Infertility. International Journal of Reproductive BioMedicine, 13(12), 801-808. 
Shevlin, M. \& Adamson, G. (2005). Alternative factor models and factorial invariance of the GHQ12: a large sample analysis using confirmatory factor analysis. Psychological assessment, $17(2), 231-236$.

Stamm, B. H. (2005). The Professional Quality of Life Scale: Compassion Satisfaction, Burnout \& Compassion Fatigue/Secondary Trauma Scales. Sidran Press.

Stamm, B. H. (2010). The concise ProQOL manual. ProQOL.org.

Şahin, N.H. \& Durak, A. (1994). Kısa Semptom Envanteri: Türk gençleri için uyarlaması. Türk Psikoloji Dergisi, 9, 44-56

Şimşek, Ö. F. (2007). Yapısal eşitlik modellemesine giriş: Temel ilkeler ve LISREL uygulamaları. Ankara: Ekinoks, 315-337.

Tabachnick, B. G. \& Fidell, L. S. (2015). Çok değişkenli istatistiklerin kullanımı. Nobel Akademik Yayincilik.

Tabatabaei, S. \& Rasouli, Z. (2018). The Reliability and validity of Persian Version of the General Health Questionnaire (GHQ-60) in Industry Staff. Iran Occupational Health, 15(3), 45-54.

Taycan, O., Taycan, S. E. \& Celik, C. (2013). The impact of compulsory health service on physicians and burnout in a province in Eastern Anatolia. Turk Psikiyatri Derg, 24, 182191

Thomas, J. T. \& Otis, M.D. (2010). Intrapsychic correlates of professional quality of life: mindfulness, empathy and emotional separation. Journal of the Society for Social Work and Research, 1, 83-98.

Uludağ, A., \& Zengin, N. (2016). Sağl1kta Şiddete Hasta Şikayetlerinde Yer Alan Olumsuz İfadeler Açısından Bir Bakış: Konya Örneği. Anadolu University Journal of Social Sciences, 16(3)71-86.

Yeşil, A., Ergün, Ü., Amasyali, C., Er, F., Olgun, N. N. \& Aker, A. T. (2010). Çalışanlar İçin Yaşam Kalitesi Ölçeği Türkçe uyarlaması geçerlik ve güvenilirlik çalışması. Archives Of Neuropsychiatry/Noropsikiatri Arsivi, 47(2), 111-117

Yılmaz, G. \& Üstün, B. (2019). Sociodemographic and professional factors influencing the professional quality of life and post-traumatic growth in oncology nurses. Journal of Psychiatric Nursing, 10(4), 241-250. 